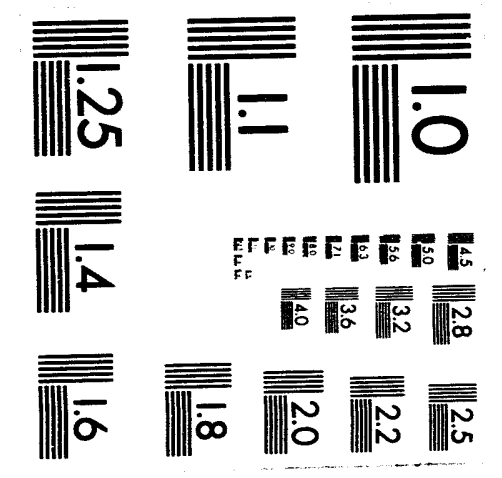



UCRL-JC-113402

PREPRINT

\title{
Shock Initiation of Nitromethane
}

\author{
C. S. Yoo and N. C. Holmes
}

This paper was prepared for submittal to the proceedings for the Joint AIRAPT/APS Conference

June 28 - July 2, 1993

Colorado Springs, CO

July 1993

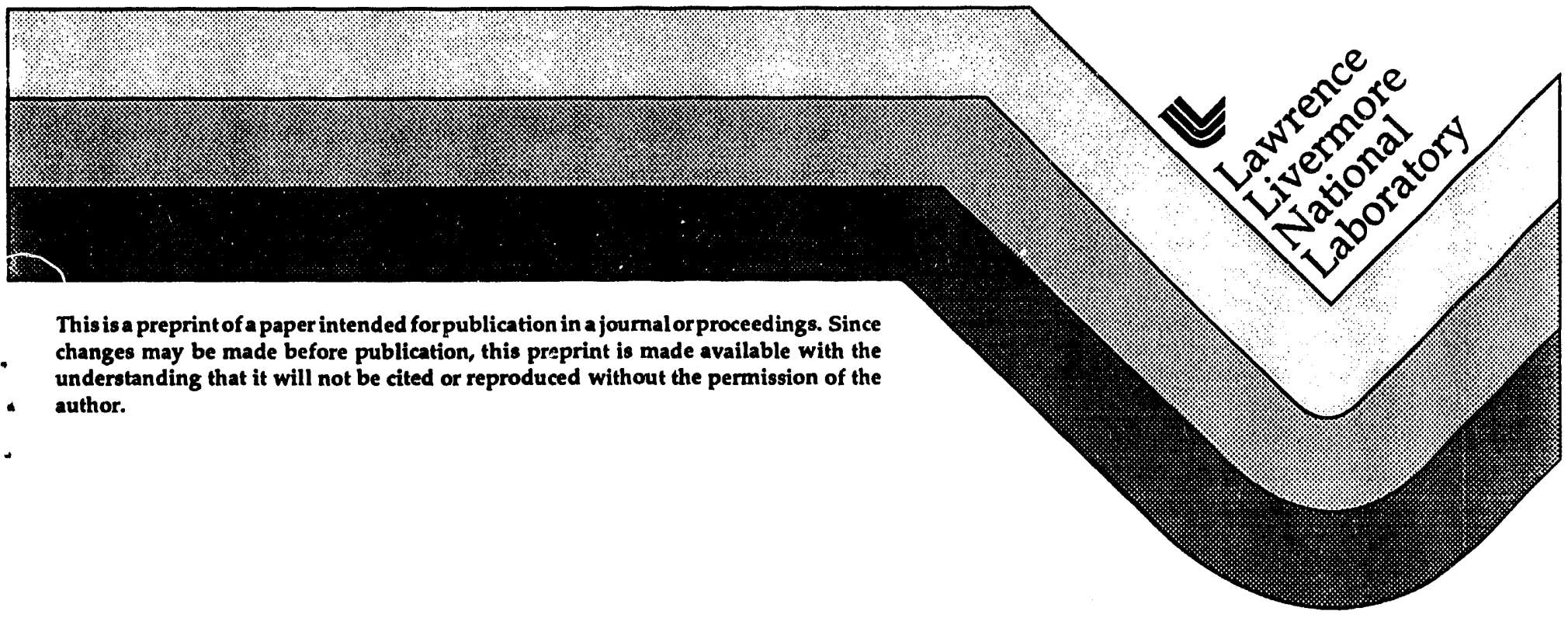




\section{Disclaimer}

This document was prepared as an account of work sponsored by an agency of the United States Government. Neither the United States Government nor the University of Callfornia nor any of their employees, makes any warranty, express or Implied, or assumes any legal llability or responsibility for the accuracy, completeness, or usefulness of any Information, apparatus, product, or process disclosed, or represents that Its use would not Infringe privately owned rights. Reference herein to any specific commercial products, process, or service by trade name, trademark, manufacturer, or otherwise, does not necessarily constitute or Imply its endorsement, recommendation, or favoring by the United States Government or the University of California. The views and opinions of authors expressed hereln do not necessarlly state or reflect those of the United States Government or the University of Callfornila, and shall not be used for advertising or product endorsement purposes. 


\title{
SHOCK INITIATION OF NITROMETHANE
}

\author{
C.S. Yoo and N.C. Holmes \\ Lawrence Livermore National Laboratory \\ Livermore, California 94551
}

The shock initiation processes of nitromethane have been examined by using a fast time-resolved emission spectroscopy at a twostage gas gun. A broad, but strong emission has been observed in a spectral range between $350 \mathrm{~nm}$ and $700 \mathrm{~nm}$ from the shocked nitromethane above $9 \mathrm{GPa}$. The temporal profile suggests that the shocked nitromethane detonaies through three characteristic periods, namely an induction period, a shock initiation period, and a thermal explosion period. In this paper we will discuss the temporal and chemical characteristics of these periods and present the temperature of the shock-detonating nitromethane at pressures between 9 and $15 \mathrm{GPa}$.

\section{INTRODUCTION}

In homogeneous high explosives like nitromethane the detonation is believed to occur by thermal explosion at the rear boundary; ${ }^{1-3}$ that is, rapid exothermic reactions which feed the energy into the shock front and increase the temperature and pressure. This chemical energy brings the unreacted high explosive at the shock front to a substantially higher thermodynamic state, the von-Neumann spike, from which the chemical reaction takes place to a steady detonation state, the C-J state. The energetics of these processes are relatively well known in many explosives, including the spike and C-J conditions, detonation wave velocity, and material velocity. However, chemistry of these processes is not well known at the molecular level. For example, it has not been understood how the shock compressed explosive initiates the chemical reaction and evolves into the detonation products like graphite, $\mathrm{H}_{2} \mathrm{O}, \mathrm{CO}$, $\mathrm{CO}_{2}$, etc.

A reasonable approach to obtain an insight of the shock initiation and detonation of high explosives is rime-resolved spectroscopy which can directly probe the chemical species and their changes in time. In this paper we report the results of emission studies of shock compressed nitromethane.

\section{EXPERIMENTS}

Figure 1 depicts three schematics of the emission experiments of shock-detonating nitromethane showing the target design and various shock states. The nitromethane is contained in a $6 \mathrm{~mm}$-thick cavity between an Al base plate and a sapphire window. The impactor is also made of aluminum and is accelerated to a velocity $2-3.2 \mathrm{Km} / \mathrm{s}$ using a 2-stage gas gun. The impedance matching technique using the Hugonior of $\mathrm{Al}^{4}$ and Mie-Gruneisen equation of state for nitromethane 5 was used to obtain the thermodynamic state of shock compressed nitromethane.

- Emissions from the shocked and detonating nitromethane is time-resolved in a direction parallel to the shock propagation. An optical fiber bundle is used to collect the emission from a smail central area of the sample where the shock state is well defined in one-dimension and, thus, provides fast time resolution that primarily depends on the
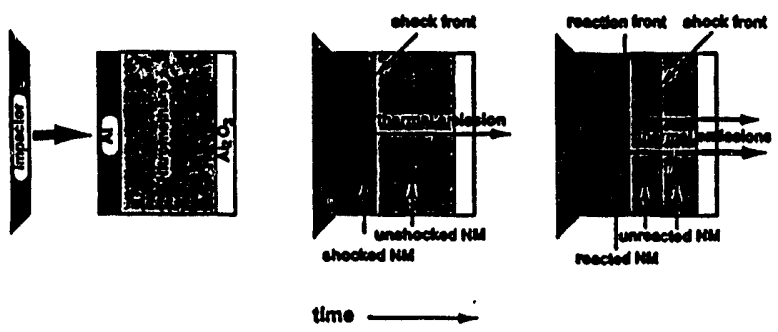

Fig 1. Schematics of the emission experiment of shocked nitromethane showing a target design and shock states.

rise time of the recording electronics. Time and spectral resolution of the system are approximately $1 \mathrm{~ns}$ and $2 \mathrm{~nm}$, respectively. The detailed description of the system can be 
found elsewhere. 6

Three instances are shown in the figure: (a) prior to the instant of impact, (b) after the impact but prior to thermal explosion, and (c) after thermal explosion. The shock temperature of nitromethane at $10 \mathrm{GPa}$ is estimated to be approximately $1000 \mathrm{~K}$. The thermal explosion temperature of nitromethane is estimated to be over $3000 \mathrm{~K}$. Based on black-body radiation the emission interisity at $1000 \mathrm{~K}$ is roughly six orders of magnitude less than that at $3000 \mathrm{~K}$ in the spectral region between $350 \mathrm{~nm}$ and $700 \mathrm{~nm}$ where the emission spectrum is recorded in this study. Therefore, thermal emission of shocked, but unreacted nitromethane is negligible.

Nitromethane has an absorption band above $300 \mathrm{~nm}$, peaking at $270 \mathrm{~nm}$. The pressure dependent shift of this band is estimated to be rather small, less than $\sim 2 \mathrm{~nm} / \mathrm{GPa}{ }^{7}$ This means that both shocked and unshocked nitromethane are optically clear in a spectral range between $350 \mathrm{~nm}$ and $700 \mathrm{~nm}$, as far as they remain unreacted. On the other hand, the reaction products of shocked nitromethane such as carbon particles and graphite are believed to be optically thick due to absorption and scattering. 8 Assuming no reactions of the shocked nitromethane prior to thermal explosion this experiment should monitor the emission coming from a thin layer at the reaction front, and its temporal change should represent the chemical evolution of shocked nitromethane at the reaction front. However, we

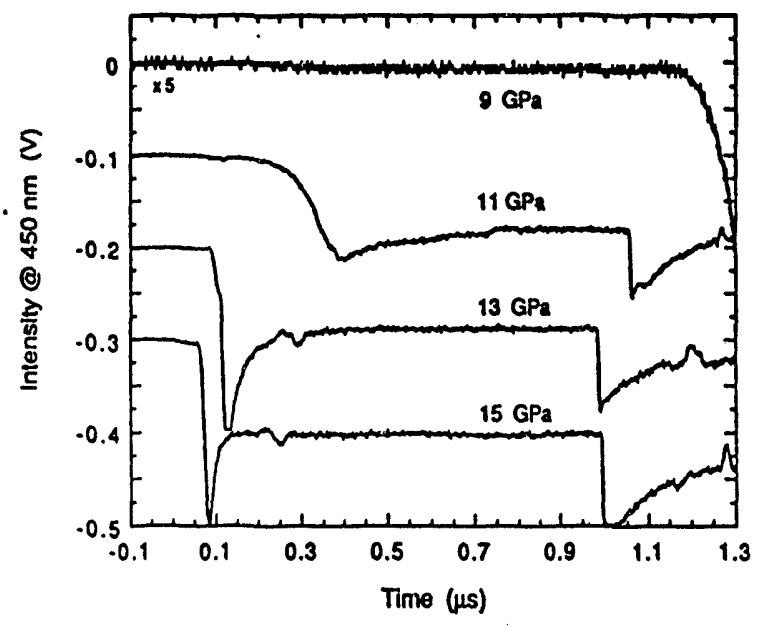

Fig 2. Time-resolved emission intensity changes of shocked nitromethane at several pressures. will see that neither is the reaction front optically thick, nor the shocked nitromethane is chemically inert or optically transparent. The emission characteristics are rather complicated by the initiation process of shocked nitromethane, which occurs prior to the thermal explosion and strongly depends on time and pressure.

\section{RESULTS AND DISCUSSION}

Figure 2 shows the temporal characteristics of emission obtained from shock detonating nitromethane at several pressures. The emission intensity peaks at some time after nitromethane is shocked and then, levels off to a steady value. The spike of the emission intensity change clearly represents a rapid exothermic chemical reaction of shocked nitromethane. This explosion time $\left(t_{C}\right)$ strongly depends on pressure. It occurs at $1.2 \mu s$ after the shock wave enters nitromethane at $9 \mathrm{GPa}$ and at $60 \mathrm{~ns}$ at $15 \mathrm{GPa}$. It is also evident at the $15,13,11 \mathrm{GPa}$ experiments that there is a small jump in the emission intensity just before it reaches a steady level. This likely represents that the reaction front catches up the shock front $\left(t_{c}\right)$. From this time on, the thermal explosion takes place directly from the unshocked nitromethane. A small rise in the emission intensity is also evident prior to the rapid rise by thermal explosion ( $t_{i} ; \mathbf{e x}$, see the 264 ns jump at $9 \mathrm{GPa}$ ). We attribute this to the initiation of shocked nitromethane before the explosion takes place. The initiation process has also been observed in the previous measurements. ${ }^{2}$ This shock-initiation may result in two consequences: smearing the explosion front and increasing the opacity of the shock-initiated nitromethane in time. The intensity decrease after the peak value may reflect those.

The chemical processes occurring in shocked nitromethane can be classified into three regions based on the temporal behavior of the emission intensity. (1) An induction period (before $t_{i}$ ) during which shocked nitromethane remains unreacted and transparent at relatively low temperature of $1000 \mathrm{~K},(2)$ a shock initiation period (from $t_{i}$ to $\left.t_{e}\right)$ in which the shocked nitromethane initiates the reaction, and finally (3) a thernal explosion period (after $t_{e}$ ) during which rapid exothermic reactions take place to produce the stable detonation products. Figure 3 shows the 
pressure dependence of the initiation and thermal explosion times, together with that of the catch-up time. While $t_{c}$ and $t_{c}$ agree well with the previous ones, this work shows that nitromethane starts the initial reaction at substantially earlier time than that reported previously. This is probably due to higher sensitivity of the current recording system.

The spectral characteristics of shocked nitromethane were also obtained after the thermal explosion occurred. However, the spectral characteristics in the initiation time period were not resolved due to the extremely low intensity (see Fig 2). Therefore, at the present time we know nothing about the spectral characteristics of thermal emission at the initiation period. In the explosion period no emission

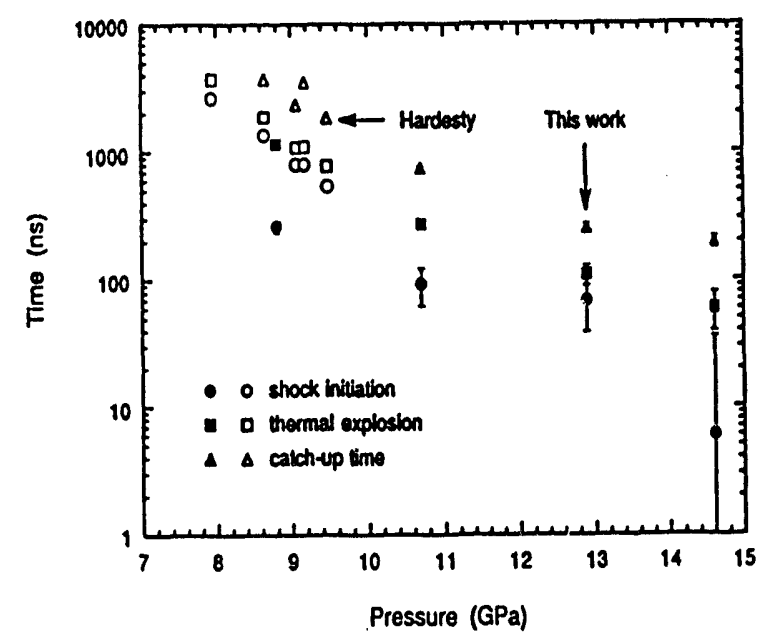

Fig 3. The pressure dependence of the initiation time, thermal explosion time, and catch-up time.

features are apparent to characterize the transients or reaction products, but there is only a broad emission band between $350 \mathrm{~nm}$ and $700 \mathrm{~nm}$. Assuming thermal emission, the temperature of shocked nitromethane can be obtained from a gray-body radiation fit. Figure 4 shows the temperatures at the spike and the steady-state, which could represent the temperatures of the reaction front of shock-compressed nitromethane (superdetonation) and of nitromethane (normal detonation), respectively. Notice that the superdetonation temperature is higher than the normal detonation temperature by $200-500 \mathrm{~K}$, which is in contrast to the previous observations. ${ }^{1}$ The steady temperature is nearly independent of pressure, $3960 \pm 40 \mathrm{~K}$, whereas the spike temperature strongly depends on pressure $\sim 60 \mathrm{~K} / \mathrm{GPa}$. This may be due to the fact that the normal detonation front is very sharp, whereas the superdetonation front is smeared by the initiation reactions occurring behind the shock front. Therefore, the reaction zone after the von-Neumann spike is extremely narrow at these pressures, and the steady temperature may represent the temperature at a condition similar to the CJ temperature. On the other hand, the superdetonation front is relatively smeared by the initiation reactions and, therefore, the emission is obtained in a relatively thick chemical region, where the temperature strongly varies with pressure.

The emission spectrum is best fit with the emissivity value 1.0 for all the experiments, representing black-body radiation. This would mean that the thermal emission likely comes from the carboneous species such as graphite. If so, the carbon nucleation and growth kinetics should be important processes occurring in this thermal explosion period.

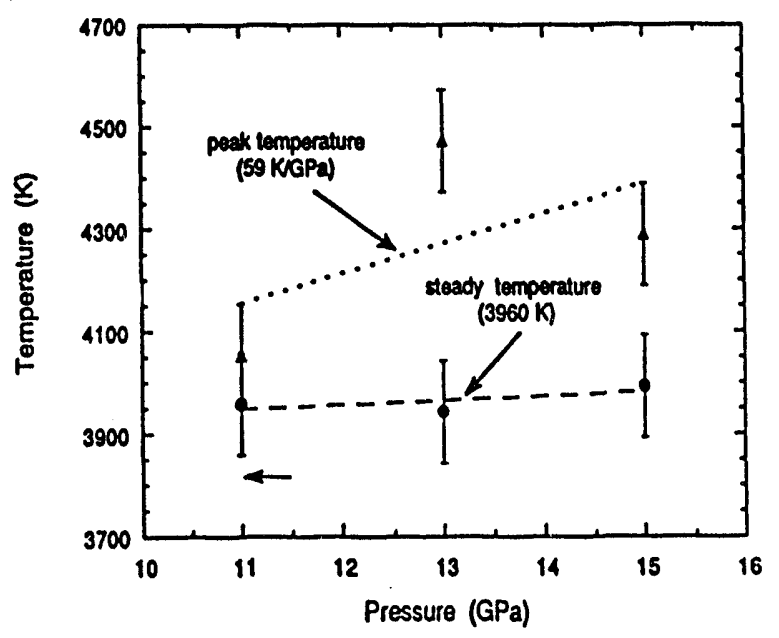

Fig 4. The temperatures of shock detonating nitromethane at several pressures.

\section{ACKNOWLEDGMENTS}

We thank Ervin See, Jim Crawford and Sam Weaver at LLNL for their technical assistance. Discussions with Clark Souers, Mat van Thiel, Francis Ree at LLNL and Steve Sheffield at LANL were extremely valuable to this study. This work was performed under auspices of the U.S. DOE by the LLNL under contract no. W-7405-ENG-48. 


\section{REFERENCES}

[1] A.W. Campbell, W.C. Davis, and J.R. Travis, Phys. Fluids 4, 498 (1961).

[2] D.R. Hardesty, Combustion and Flame 27, 229 (1976).

[3] S.A. Sheffield, R. Engelke, and R.R. Alcon, "In-situ study of the chemically driven flow field in initiating homogeneous and heterogeneous nitromethane explosives" in Proceedings of the Ninth International Symposium on Detonation, pp 39, Portland, Oregon (1989).

[4] A.C. Mitchell and W.J. Nellis, J. Appl. Phys. 52, 3363 (1981).
[5] R.W. Woolfolk, M. Cowperthwaite, and R. Shaw, Thermochimica Acta 5, 409 (1973)

[6] C.S. Yoo, N.C. Holmes, and E. See, in Shock Waves in Condensed Matter -1991, edited by S.C. Schmidt, R.D. Dick, J.W. Forbes, D.G. Tasker, pp733 (NorthHolland, Amsterdam, 1992).

[7] J.M. Winey, Y.M. Gupta, and K.G. Casey, in this proceeding.

[8] N.C. Holmes, Rev. Sci. Instrum. 64, 357 (1993); N.C. Holmes, G. Otani, P. McCandless, and S.F. Rice, in Proceedings of the Ninth International Symposium on Detonation, pp 88, Portland, Oregon (1989). 

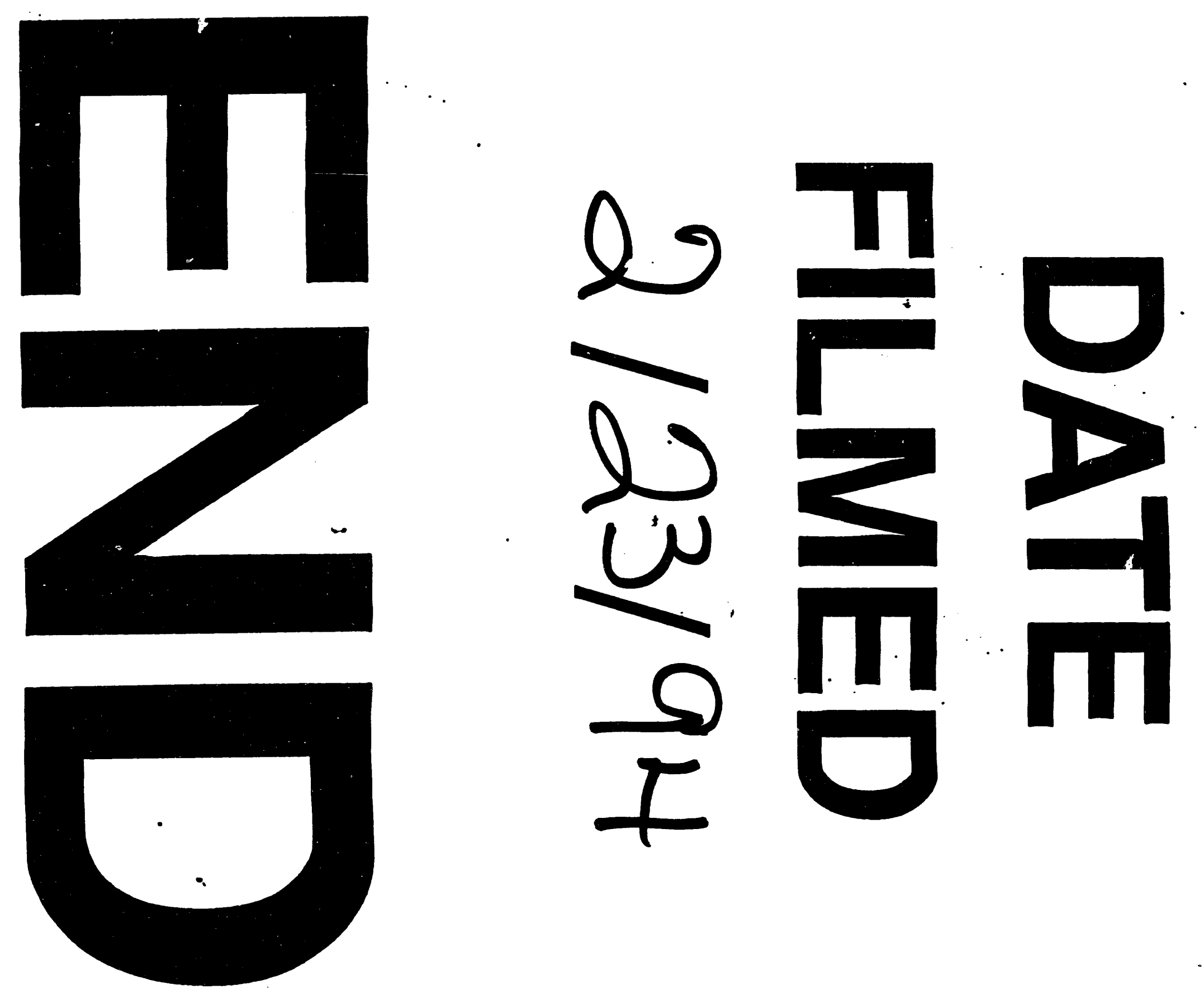
